\title{
The missing link of crime analysis: a systematic approach to testing competing hypotheses
}

Michael Townsley, Monique Mann and Kristian Garrett

Key Centre for Ethics, Law, Justice and Governance

School of Criminology and Criminal Justice

Griffith University

Brisbane, Australia

Abstract

Crime analysts have traditionally received little guidance from academic researchers in key tasks in the analysis process, specifically the testing of multiple hypotheses and evaluating evidence in a scientific fashion. This article attempts to fill this gap by outlining a method (the Analysis of Competing Hypotheses) of systematically analysing multiple explanations for crime problems. The method is systematic, avoids many cognitive errors common in analysis and is explicit. It is argued that the implementation of this approach makes analytic products audit-able, the reasoning underpinning them transparent and provides intelligence managers a rational professional development tool for individual analysts.

Key words: crime analysis, problem solving, testing hypotheses, competing hypotheses, falsification

WORD COUNT: 6300 


\section{Introduction}

The analytic landscape of law enforcement and intelligence agencies has changed dramatically over the last decade in terms of procedures, capabilities and mission (Innes, Fielding, and Cope, 2005; Ratcliffe, 2008). The implementation of the National Intelligence Model in the UK, the voluminous amount of data now available in electronic form (and the storage capacities to match), the evolving remits of agencies (involving increasing priorities to security, third party policing, and intelligence led policing) are but some of the factors moulding the practice of operational analysts. The result of this change means that analysts, those professionals in law enforcement, government agencies, security and other regulatory/oversight bodies responsible for monitoring, evaluating and interpreting the criminal environment (Ratcliffe, 2008), now play a much more central and pivotal role in the crime reduction endeavour than in the past (Cope, 2004; Mazerolle and Ransley, 2005; Ratcliffe, 2008). There has been a corresponding move toward professionalising the analyst role, with the incorporation of associations (e.g., the International Association of Crime Analysts and the Association of Crime and Intelligence Analysts) and providing a career structure.

The work of analysts in interpreting the criminal environment can be thought of in similar terms as a physician diagnosing a patient. Characteristics of the problem are catalogued and speculative explanations are forwarded for further consideration. Those diagnoses inconsistent with the available evidence are rejected, with those consistent being retained. If several explanations survive there is further probing of the problem, more data collected 
The missing link of crime analysis

until, hopefully, a single explanation survives. Crime analysis is akin to solving a mystery (why does this suburb have more burglaries than its neighbouring cousin?), but one that involves many related crime scenes and the culprit is more often a situational feature than an individual.

The central argument of this article is that moves towards operational decision making being informed by analysis products are justified on scientific or objective grounds in principle, but there is a disconnect with practice. Crime analysts have traditionally received little guidance from academic researchers in key tasks in the analytic process, specifically the testing of multiple hypotheses. Managers of crime analysts rarely receive training in what analysis is and what makes a good analytic product (Ratcliffe, 2008). This article fills this gap by outlining a method of systematically analysing multiple hypotheses for crime problems.

The remainder of the article is structured as follows: the next section briefly introduces problem-oriented policing, the major paradigm that underpins much analysis in a policing context, and then explores in detail the analysis phase of problem solving. Following this, two models of crime analysis are discussed with a view to highlighting commonalities as well as conceptual gaps. The fourth section outlines the major cognitive biases that bedevil analysts. The next section describes Analysis of Competing Hypotheses $(\mathrm{ACH})$, an intuitive, structured method of evaluating evidence for and against a range of hypotheses, designed to avoid three common cognitive biases in decision-making. The penultimate section presents the analysis of an hypothetical crime problem using $\mathrm{ACH}$. The concluding section sets out some considerations for employing this technique in a law enforcement 
setting.

\section{Problem Orientation and Problem Solving}

Problem-oriented policing (POP) is a dramatically different way of framing the task of policing (Goldstein, 1979, 1990), although it has much wider implications than law enforcement problems and responses (Mazerolle and Ransley, 2005; Sparrow, 2000). Problem-oriented policing is founded on two premises. First, the fundamental unit of police work is a problem, not an individual incident. Second, law enforcement organisations should be focused on dealing with the underlying causes of problems, rather than rely on criminal justice system mechanisms to address perpetrators of individual incidents. The promise of POP is that the resolution of problems fosters a 'proactive and preventative' method of delivering police service over the traditional 'reactive incident-driven' style of policing (Knutsson, 2003, 2). Although POP has been described as 'straightforward' and 'commonsensical' there have been major impediments to POP being a routinised policing strategy (Clarke and Goldstein, 2003, p. 285; see Goldstein, 2003 for a full description).

The means of identifying, defining and diagnosing crime problems is known as problem solving. It involves 'careful, in-depth study' (Goldstein, 2003, 14), identifying the causes of crime problems and targeting tailor-made interventions at the "pinch points" of such problems (Knutsson, 2003; Read and Tilley, 2000). Clarke and Goldstein (2003) describe problem solving as an incremental method of data collection, hypothesis development and redefinition, analysis, response implementation and appraisal. The major hindrance to problem solving being routinely employed is the requirement for 'considerable experience, 
The missing link of crime analysis

skill and technical knowledge to practice it' (Knutsson, 2003, 5).

To continue the medical analogy, problem solving is akin to diagnosing a patient. The list of symptoms is evaluated and plausible explanations are generated. Problem-orientation, then, is the treatment - the actions of capable and interested stakeholders in alleviating the problem. In other words, what is done to remedy illness and return the patient to full health. It follows that understanding the factors that allow a crime (or health) problem to exist is paramount; the absence of a complete appreciation of the dynamics of a crime problem mean that deployed tactics (or treatment) will probably fail (Goldstein, 2003).

The focus of this article is on refining the stage of analysis as a single, but integral, phase of the entire process of POP; as such it will be addressed in detail below, before outlining the two main process models of analysis that have been presented in the POP literature.

\section{ANALYSIS}

Problem solvers are required to 'undertake a slow, methodological analysis' (Clarke and Goldstein, 2003, 285) in order to identify the factors that allow a problem to manifest.

Some criteria determine the likelihood that this will lead to insightful information:

1) Knowledge of appropriate theory. Theory informs what data is important to collect by virtue of predicting important and established relationships.

2) Collection of accurate data. Data are either primary or secondary in nature.

Secondary data constitutes information collected for a purpose that is different to its application. This is commonplace in law enforcement agencies where recorded crime data is collected for the purpose of investigative support and not analytical 
The missing link of crime analysis

need. Primary data is information collected and used for a single purpose. An analyst that designs a victimisation survey and uses the results to inform a repeat victimisation policy is using primary data. Primary data tends to be more accurate, but much more resource intensive to collect.

3) An established process of combining data and theory to infer the "cause" of a problem. Analysis needs to be more than summarising or describing the problem. Active ingredients need to be identified in a conclusive way to influence decision makers.

Readers who have spent time around operational analyst teams will be aware that is it rare indeed that these three conditions co-occur. A detailed treatment of the reasons for this is beyond the scope of this article, but Goldstein (2003) and Ratcliffe (2008) outline a number of reasons: there is currently not a body of knowledge in support of good practice; there is a lack of career paths for analysts; traditionally the role of analyst has had little cache in law enforcement agencies; there are limited training opportunities; and line managers are often at a loss for ways to professionally develop analysts (probably because they themselves receive little training). For an academic treatment of these issues, see Cope (2004) or Innes et al., (2005).

In order to overcome such difficulties, Goldstein (2003) recommends that police officers be trained in how to effectively analyse problems, or the organisation should develop a new role of problem analyst, appointed to analyse crime problems. To achieve the goals of both POP and crime analysis it is imperative to train and employ individuals who are able to provide the 'necessary analytic support' (Clarke and Goldstein, 2003, 289). Unfortunately, 
The missing link of crime analysis

Knutsson $(2003 \mathrm{~b}, 6)$ claims there is a 'serious lack of people with the required analytic skills', a point echoed by Ratcliffe (2008).

While there is an undoubted training need, it is also argued that a major obstacle to the routine production of high quality analytic products is that the process of analysis is not explicit, readily accessible and easily understandable.

\section{Models of Analysis}

Two models of analysis have been presented in the problem solving literature. Weisel $(2003,115)$ defines analysis as 'an iterative process of developing and testing provisional hypotheses, often through the collection of primary data'. Similarly, Ekblom $(1988,1)$ defines crime analysis as a preventative process and a 'key process aimed at conceiving, implementing and evaluating measures to prevent crime'. Weisel (2003) comments that crime analysis is more than the collection of data about a crime problem; data must be interpreted before it can be regarded as meaningful information. Therefore analysis is defined as the systematic gathering of data and the process of inferring meaningful relationships from data.

The process of analysing crime problems has been overlooked in the POP literature. Although problem solving is depicted as a straightforward and linear process, Weisel (2003) argues that little, in fact, is known about the actual process that problem solvers employ and that 'key analytical tasks necessary for problem solving have not been clearly articulated and sequenced, making analysis an ambiguous process in which objectives are unclear, data often weak and incomplete' (p. 116). For instance, she observes, that '[i]n a 
The missing link of crime analysis

52-page guide for law enforcement published by the U.S. Department of Justice about the analysis of problems, Bynum [the author] dedicates a single paragraph- actually a single sentence- to the actual analysis of data' (Weisel, 2003, 134, emphasis added).

A number of authors have argued that the process of problem analysis is one that intimidates police practitioners and has not been appropriately or functionally revolutionised from the processes employed by social scientists (Knutsson, 2003; Townsley, Johnson, and Pease, 2003; Weisel, 2003). Ekblom refers to crime analysis as an 'exploratory process', and makes an interesting analogy that it should be regarded as 'more akin to composing a picture than to the slavish following of the fixed steps of a cookery book' (Ekblom, 1988, 1). Ekblom outlines a range of techniques (e.g. mapping, tables of frequencies, cross tabulations) that analysts should be able to employ but asserts these cannot be applied in a strictly prescriptive fashion, that the nature of the problem and putative hypotheses determine the ordering of their utilisation. It is for these reasons that it is asserted that '...additional guidance on analysis is necessary' (Weisel, 2003,117)

\section{Process of Analysis}

Weisel (2003) calls for greater attention to be paid to analysis as a process. Ekblom (1988) describes the process of analysis as acquiring detailed information and exploring the information to identify patterns; although there is no definite explanation of how this should be completed. Weisel is more declarative, and outlines a model consisting of three major stages: 'documentation of the problem', 'data collection' and 'analysing and interpreting the findings' $(2003,118-119)$. This method of analysing problems is one that 'involves sequencing research steps', travelling from the broad to the specific, moving down the 
The missing link of crime analysis

funnel, in a systematic manner (Weisel, 2003, 128; 137). In the opinion of Weisel (2003, 135) 'this sequencing ... is a key element of solving problems'.

\section{Cataloguing Symptoms of Problems}

A crucial stage in the course of analysis is the identification of relevant variables through the 'examination of existing data' (Weisel, 2003, 129). Goldstein (1990, 36-37) highlights that in order to accurately diagnose the crime problem the analyst must undertake an examination of 'all the characteristics of a problem and all the factors that contribute to it'. This is 'identifying [the] contextual variables' which should be done as 'early as possible in the analysis process' (Weisel, 2003, 126-128).

Symptoms are identified by utilising experience and/or academic theory. The main difference between the two is that experience constitutes an implicit theory of crime or criminality but academic theory is located in a recognised, explicit body of knowledge. A chief advantage of academic theories is they are explicit, have been subject to testing, have some evidence to support them and have been exposed to critical evaluation. The same cannot be said of experience. This, of course, is not to say that all academic theories will out perform experience nor that experience is irrelevant. Experience is highly variable at the analyst level. The danger of implicit theories is the false sense of validity.

Ekblom's compendium question is a useful guide to frame this step:

the core of the analysis can be summarised in a 'compendium' question: what offences occurred; where, when, under what circumstances and by what method were they committed; and who or what was the victim or target? The answer to the question can contribute to an understanding of the crime pattern, the criminal 
The missing link of crime analysis

opportunities that underlie it, and the scope for prevention.

Ekblom, (1988, p11)

Essentially, asking these questions contributes to the analysts' understanding of the potential cause(s) of the crime problem. It is essential to identify such variables before attempting to generate testable hypotheses'. According to Weisel $(2003,126)$, 'the articulation of testable hypotheses relies on generating a range of variables that are presumed to be associated with the problem. These contextual variables are factors that have the potential to shed new light on the causal sequencing of the problem being examined.' Ekblom (1988) emphasises the need to identify the symptoms of the crime problem (i.e. variables/factors) and a range of putative diagnoses (i.e. hypotheses). While lists of possible variables/factors that may inform the development of hypotheses are presented, no detail is given as to how different competing hypotheses are evaluated and/or combined before a final diagnosis is attained.

\section{Hypothesis Generation and Testing Should be Explicit}

Once the key contextual variables have been identified, the next stage of analysis is to develop testable hypotheses about the crime problem. While hypothesis is the conventional term used by scientists, "explanations" can be used if preferred. They are simply statements about the problem in question that may or may not be true. The role of the analyst is to identify and consider these explanations and judge, based on the data collected, which best reflects the evidence. Two scientific principles should inform hypothesis generation: (a) several hypotheses should be generated for consideration and (b) they need to be testable. Thus, developing multiple testable hypotheses leads to the 
The missing link of crime analysis

elimination of explanations that are not supported by empirical evidence. Explanations that survive this process enable the analyst to interpret the causal factors of the crime problem.

Although both Weisel and Ekblom stress the importance of developing multiple testable hypotheses neither elaborate on how this might be done. Hirschfield (2005) lists a number of questions that need to be posed and decisions that need to be made, in order for crime analysis outcomes (i.e. hypotheses) to be valid. However, he does not specifically outline how these 'outcomes' are determined to be the cause of the crime problem or which hypothesis is correct amongst a myriad of competing potential hypotheses.

Weisel (2003) argues that employing Popper's concept of falsification ii is a crucial method in problem solving, however an explicit and unequivocal method for this process is not provided. Trained researchers have at their disposal a range of techniques that are designed to locate patterns or relationships in data while providing a degree of protection against spurious results. These techniques - research methods and experimental design are a distillation of the scientific method and have been developed over centuries to address common research questions (e.g. does A cause B?). Weisel $(2003,131)$ argues that the 'sequencing of data collection and analysis- collect, analyse, revise hypothesis; collect, analyse, revise hypothesis- is intuitive for experienced researchers. However, it needs to be made more explicit to offer guidance for problem solvers with less experience'. The issue is compounded given that analysts have traditionally received very little in the way of training. Without an established set of tools (techniques and processes) analysts are unlikely to avoid pitfalls of reasoning iii. The next section outlines some of the implications of reasoning in the absence of a set of reliable techniques for inferring 
The missing link of crime analysis

relationships.

\section{Cognitive Biases that Influence Analysts}

There is substantial evidence in the cognitive psychology research literature that demonstrates that decision makers and analysts employ cognitive strategies in order to efficiently process large amounts of complex information. These strategies are known as heuristics, or mental short cuts, and serve the purpose of simplifying the process of decision-making. Although often advantageous and necessary to ease the burden of comprehending large amounts of data and complex relationships, these subconscious mental processes often result in predictable errors and 'faulty judgments' which are known as cognitive biases (Heuer Jr., 1999, 111). Cognitive biases have been investigated with respect to both intelligence analyst and medical practitioner decision making processes, which are closely comparable to analysts attempting to diagnose crime problems (see Groopman, 2007; Heuer Jr., 1999; Johnston, 2005; Kebbell et al., 2010 for full discussion). There are many different cognitive biases that may influence analysts' decision making and operate at different stages throughout the course of problem analysis. The following list is aligned with the major stages of analysis.

\section{Collection of Data}

At the earliest stages of analysis, the analyst's prior assumptions and beliefs about a crime problem may influence the search for data, and the analyst subsequently collects evidence that is consistent with, and confirms such expectations. This is known as confirmation bias and is argued as being the most commonly occurring form of cognitive bias. Confirmation 
The missing link of crime analysis

bias is defined as the 'tendency to select evidence that supports rather than refutes a given hypothesis' (Johnston, 2005, 21). Not only does this definition suggest that analysts are influenced by their prior expectations, it also highlights that individuals, unless trained otherwise, intuitively search for information that is likely to confirm their hypotheses rather than disconfirm them. This tendency is a major motivation for the move toward falsification.

\section{Assessing Likelihood of Events}

When attempting to ascertain the likelihood or frequency of events occurring, two main heuristics are employed by analysts (Tversky and Kahneman, 2000). The first of these is the availability rule, the ease with which similar events come to mind or the number of such events that are remembered. This can cause bias in decision making as both factors are unrelated to the actual frequency of the event occurring (Heuer Jr., 1999). The second heuristic is the anchoring rule, estimating how likely an event is to occur by establishing a baseline estimate (from experience or previous assessments) and then adjusting this according to new information. In this case, bias occurs if adjustments are smaller than expected, reflecting the tendency to overly rely on the baseline assessment (the "anchor") (Heuer Jr., 1999).

\section{Evaluation of Evidence and Variables}

When evaluating evidence and potential variables, analysts' decision making is influenced by several biases. The vividness criterion demonstrates that evidence that is 'vivid, concrete and personal' influences decision making more than information that is abstract or statistical, regardless of the actual value of the evidence (Heuer Jr., 1999, 116). Stories have more impact than statistical tables. 
The missing link of crime analysis

Entry-level analyst positions involve data collection, data collation, assessment and reporting tasks. If promoted to more senior roles, less time is spent on collection and collation tasks in favour of evaluating the merit of analytic products. Yet personal experiences have a enduring hold on decision making processes, especially when new information comprises reports of aggregated and synthesised information rather than experiential knowledge. The vividness criterion, in conjunction with the availability rule, can result in a type of analytic Alzheimer's. In its extreme form, only early well-formed memories are retained and new information has an ephemeral impact.

\section{Perception of Causality in Hypothesis Generation}

When generating hypotheses, analysts typically prefer causal explanations (Heuer Jr., 1999). According to Heuer Jr. $(1999,129)$ 'coherence implies order, so people naturally arrange observations into regular patterns and relationships'. However, such patterns and relationships may not be accurate and 'chance or randomness' explanations are more valid. Related to the concept of causal explanations is the bias of illusory correlation. This bias occurs when analysts 'perceive a relationship that does not in fact exist' (Heuer Jr., 1999, 141). The axiom 'correlation does not equal causation' is relevant to analysts when generating hypotheses about the causes of crime problems. Heuer Jr., (1999) emphasises that factors may be correlated because they have a mutual cause, rather than due to a cause and effect relationship.

Another important bias, search satisficing, operates in the evaluation of evidence. This can occur when analysts generate and test hypotheses sequentially rather than concurrently. If hypotheses are considered one at a time there is a tendency to 'stop searching for a diagnosis' at the first explanation that appears to fit the available evidence (Groopman, 
The missing link of crime analysis

$2007,169)$. The consequence of this bias is identifying the correct explanation for a problem is related to the order in which hypotheses are considered, which can result in neglecting important aspects of the crime problem, such as multiple diagnoses or causes of the crime problem.

\section{Post-Response Assessment}

When assessing the effectiveness of responses to crime problems, and the accuracy of the hypotheses, analysts may be susceptible to hindsight bias. Hindsight bias occurs when 'analysts overestimate the accuracy of their past judgments...underestimate how much

they had learned... [and] judge that events were more readily foreseeable than was in fact the case' (Heuer Jr., 1999, 161). This is an important bias when evaluating the effectiveness of responses (which are aligned with the causal factors of the crime problem), because reductions in the crime problem may not be due to the response, but to extraneous factors. Importantly, once analysts are aware of the outcome of a crime reduction initiative, it is difficult to envisage alternative explanations. This may result in the original hypotheses being accepted as explaining the true causes of the crime problem, when in fact it does not.

\section{Overcoming Cognitive Biases}

To overcome such errors in judgement and decision-making, changes to the way analysts operate need to be implemented. Johnston (2005, pp. 9-10) argues that 'systematic performance improvement infrastructures' should be implemented to minimise cognitive errors. When attempting to make a medical diagnosis, Groopman (2007, 278-279) argues that cognitive errors can be minimised by patients questioning their physician with three questions: 
The missing link of crime analysis

1. 'What else can it be?';

2. 'Can two things be going on to explain my problem?'; and

3. 'Is there anything in my history or physical examination or lab tests that seems to be at odds with the working diagnosis?'.

In answering these questions the physician can guard against the cognitive biases discussed above, especially search satisficing and confirmation bias. Through questioning 'what else could be causing the symptoms?' physicians are compelled to generate alternative diagnoses and choose the diagnosis that has the least number of inconsistencies.

The obvious question then is, what questions should crime analysts ask? The aforementioned literature suggests that, unlike physicians, analysts do not have the training, line management nor the established body of knowledge of best practice to use an analogous set of questions. The next section introduces a method for evaluating multiple hypotheses simultaneously and protecting against the major cognitive biases most commonly associated with the analytic process.

\section{Analysis of Competing Hypotheses}

Analysis of Competing Hypotheses $(\mathrm{ACH})$ is a method of weighting alternate explanations and conclusions for a given problem (Valtorta et al., 2005). Originally designed by Heuer Jr., (1999) for use by practitioners within the intelligence field, ACH presents a systematic approach to decision making. In light of this, $\mathrm{ACH}$ may be useful in addressing many of the 
The missing link of crime analysis

key problems associated with crime analysis at present. These problems, as discussed previously, include a lack of explanation or guidance in the relevant literature as to how hypotheses are formed by problem solvers (Weisel, 2003, 117), an absence of clear explanation as to the process through which analysis is performed (see Ekblom, 1988; Weisel, 2003) and clarification as to the appropriate selection and weighting of relevant variables. $\mathrm{ACH}$ is a system that is explicit in what evidence is used, how evidence is considered and the process by which analysis of rival explanations is conducted.

Heuer Jr., (1999) lists several key elements of ACH which make it distinct from other forms of analysis and suggest that it could be employed effectively in the analysis of crime problems. These are, first, the ACH process is initiated by generating a list of possible alternate hypotheses for a given problem, rather than limited to only the single likely alternative an analyst wishes to validate. The objective is to ensure that multiple hypotheses are considered and explored in equal fashion. Second, $\mathrm{ACH}$ seeks to pinpoint and highlight those items of evidence that have the greatest "diagnostic value" in determining the likelihood of a given hypothesis. Third, $\mathrm{ACH}$ operates conversely to conventional forms of analysis by 'seeking evidence to refute hypotheses' (Heuer Jr., $1999,108)$, rather than looking for evidence in order to verify a perceived likely hypothesis. Focus is placed on identifying evidence or information that weakens a hypothesis, rather than evidence that supports it. In this regard $\mathrm{ACH}$ is closely aligned with the scientific method and the concept of falsification. 
The missing link of crime analysis

\section{$\mathrm{ACH}$ : An 8 Step Process}

As originally described by Heuer Jr., (1999), ACH consists of eight straightforward steps (Wheaton and Chido, 2006). The following is a brief synopsis of each of these eight steps in order of process, although the remit of this article focuses on the first five steps. It is assumed that analysts are familiar with data collection and collation tasks, so these are not emphasised here. The following section contains a brief case study of $\mathrm{ACH}$ applied to a crime problem.

\section{Step 1: Hypothesis Generation}

The first step of the $\mathrm{ACH}$ process involves generating a list of possible hypotheses relevant to the specific problem. Heuer Jr. (1999) suggests that this step is generally best conducted in a group environment to maximise both the number and diversity of potential hypotheses. Following this, hypotheses are subsequently screened through a process of implied feasibility. Heuer Jr. (1999) states that there is no 'correct' answer to the number of hypotheses that should be included for analysis of any given problem, but rather implies that it should be dependant on the nature of the specific problem and proportionate to both the level of uncertainty surrounding the problem and the degree of impact generated by resultant policy decisions.

\section{Step 2: Generation of Evidence and Arguments}

The second step in the $\mathrm{ACH}$ process is to list items of evidence and related arguments supporting each possible hypothesis. Types of evidence included should cover a broad range of assumptions and deductions. The generation of evidence is the result of data 
The missing link of crime analysis

collection and collation tasks, ideally underpinned by an explicit theory of the problem.

Step 3: Preparation of Analysis Matrix and determination of "Diagnosticity" of Evidence This step is arguably the most important in the $\mathrm{ACH}$ process. The purpose is to determine the extent to which each hypothesis is consistent with the evidence. First, a matrix of hypotheses (columns) and evidence (rows) is created. Next, each piece of evidence in relation to the hypotheses is examined. The analyst needs to determine if the hypotheses are consistent, inconsistent or irrelevant with respect to the evidence. It is important to do this row-by-row; consider one piece of evidence and move across columns. Repeat this for each row until all pieces of evidence have been assessed. The risk of search satisficing occurs only if the matrix is processed column-by-column. If a column is shown to be consistent with all the evidence there is a tendency to suspend further analysis, thereby ignoring hypotheses (columns) yet to be considered. Processing the matrix row-by-row avoids this.

\section{Step 4: Refining of Matrix/Reconsider Hypotheses}

The key feature of $\mathrm{ACH}$ that sets it apart from traditional analysis is determining the "diagnosticity" of each item of evidence. This property is the magnitude of influence on the relative likelihood of the hypotheses. Evidence that is consistent with all hypotheses has no diagnostic value because it does not reveal anything about the underlying cause; we are no wiser because of its inclusion. Evidence that discriminates between hypotheses is said to have diagnostic value. 
The first task in this step is to cross out, but not remove, evidence with no diagnostic value. The second task is to revisit each hypothesis with a view to assessing whether they need rewording, possibly combining or the introduction of new hypotheses if necessary. Combining hypotheses is warranted if the available evidence fails to distinguish between them, suggesting they share many characteristics, or one is a proxy of the other. Additional hypotheses may present themselves once a deeper understanding of the problem emerges and as a result of considering the evidence. While care needs to the taken to avoid "moving the goalposts" during analysis, it is inevitable that a deeper understanding the problem will be gained simply by evaluating the evidence and hypotheses. Refining the matrix, by deleting evidence and modifying hypotheses, is therefore an acceptable approach to consolidate this increased knowledge.

Step 5: Drawing of tentative conclusions in relation to the relative likelihood of each hypothesis/attempt to disprove hypotheses

Here the completed and revised matrix is examined in order to compare competing hypotheses. Hypotheses should be ranked according to the number of inconsistencies they display with available evidence (Heuer Jr., 1999). The frequency of inconsistent information is tallied for each column. The one with the smallest amount of disconfirming information is considered a more powerful explanation.

\section{Steps $6,7 \& 8$}

These final three steps involve first reviewing the rankings of each hypothesis and reanalysing each piece of evidence, questioning those which appear misleading or require more information to be substantiated (Heuer Jr., 1999). Following this is the report stage, where the relative likelihood of each hypothesis, not just those that are the most 
The missing link of crime analysis

probable/least inconsistent, should be considered. Finally, milestones are identified for monitoring purposes. The way these steps are carried out will differ from organisation to organisation, so no further comment is made.

\section{Case study}

An hypothetical crime problem is outlined in order to illustrate the $\mathrm{ACH}$ method. Space restrictions preclude an extended treatment, but the example contains sufficient detail for readers to understand the individual steps involved and the benefits the $\mathrm{ACH}$ method brings to the analysis of crime problems.

\section{Problem Scanning (ACH Step 1)}

An inner city area, synonymous with severe deprivation, has experienced a sharp increase of incidents of street robbery attracting significant media attention and considerable pressure from Headquarters. The first step for the analyst is to establish a set of plausible hypotheses and seeks views from key agencies in the area: police, youth services and education.

Police officers suggest the incidents are largely acquisitive in nature and driven by poverty. Local teachers admit long standing bullying problems exist within schools, along with constant reports of stealing. A youth worker suggests loosely formed 'gangs' of youth are responsible for the increased spate of street crime. Individuals engage in risky behaviour 
The missing link of crime analysis

in the form of dares and challenges to establish membership credentials and status in the group. Committing acts of violence confers considerable respect.

\section{Symptom collation (ACH Step 2)}

The previous three months of robbery incidents (i.e. recorded crime data) are used to establish the evidence used to test the hypotheses. The analytic strategy includes developing a coding frame and searching for patterns (Parts 2 and 3 of Ebklom's crime analysis model), both of which are underpinned by Ekblom's compendium question and environmental criminology theories. Assume that similar data are extracted for the entire city to serve as a baseline (an alternate baseline could be established using robbery incidents in the local area prior to the recent spike). Differences between the problem area and the baseline are of particular interest, because they could reveal information about the recent increase in robberies. The process yields the following key observations:

- $80 \%$ of the victims are restricted to a narrow age range (13--16 years), compared to $30 \%$ for the entire city;

- over $90 \%$ of incidents occur in the streets surrounding a major public transport terminal during certain hours (1500--1800 hours) on weekdays (this pattern is observed in only $45 \%$ of robberies for the city);

- the offenders' age profile is very similar the victim age profile above;

- there is not enough information to suggest whether the offenders are from a different school than the victim; and

- detailed reading of MO fields reveal a peculiar pattern where an offender returns stolen items to the victim (during the incident) in full view of the offender's peer 
The missing link of crime analysis

group. While only accounting for $20 \%$ of the robberies, it seems reasonable to infer that for these incidents offenders are seeking to humiliate victims. The remainder of the incidents involve the permanent loss of items.

\section{Problem analysis (ACH Step 3)}

The strength of the hypotheses can now be assessed. The matrix is shown in Table 1.

$$
\text { [insert Table } 1 \text { about here] }
$$

As explained in Section 5, each piece of evidence is assessed in light of the hypotheses, in turn. It is important to move across the row considering each column so that $\mathrm{E} 1$ and $\mathrm{H} 1$ is the first, then $\mathrm{E} 1$ and $\mathrm{H} 2$ second, then $\mathrm{E} 1$ and $\mathrm{H} 3$. Next is $\mathrm{E} 2$ and $\mathrm{H} 1$, and so on.

Space restrictions prevent a full description of the logic used to populate the matrix, but a terse justification is provided in the Appendix. Where evidence confirms an hypothesis a plus symbol is used, with disconfirmation indicated by a minus sign. Neutral or irrelevant information is indicated by zero. If the evidence strongly (dis)confirms the hypothesis, the number of symbols used can be doubled. The matrix reveals that the bullying explanation has the least disconfirming evidence associated with it, based on the set of problem characteristics provided. The explanation with most disconfirming information is the acquisitive explanation.

In this abstracted example, only secondary data sources were used. From here, the analyst should attempt to weaken each explanation by drawing on further secondary data sources, or engage in primary data collection. The latter option is more desirable as it 
The missing link of crime analysis

should provide very targeted evidence, but it does have higher opportunity costs. An obvious candidate for primary data collection is to conduct interviews with victims and other people similar to the victim and offender groups to learn what is happening. This should provide sufficient insight to discriminate between the strengths of different explanations.

\section{Conclusions}

This article reviewed the literature on problem solving and crime analysis and identified a gap in describing the process of testing hypotheses. Given the potential of cognitive biases to operate in decision-making, the $\mathrm{ACH}$ method was proposed to fill this gap. One of the chief benefits of the $\mathrm{ACH}$ method relevant to crime analysis is that a single complex analytical question (what is causing the robbery problem?) involving multiple answers, with considerable contrasting evidence, has been converted into 15 simple yes/no questions (= 3 explanations multiplied by 5 pieces of evidence). This transforms the mechanics of the analysis into a much more manageable process.

Also important is the fact that the process is now transparent and audit-able. The reasoning for each of the 15 decisions is contained in the Appendix. Readers may disagree with the logic or hypotheses or evidence, but the basis for the decision is very clear. It is now possible to debate why determinations of analysts differ. This alone provides intelligence managers with a constructive means to illustrate areas for improvement in analytic products. Moreover, in order to complete the matrix, it was necessary to break down thinking in a piecemeal fashion and by doing so, mitigate against 
The missing link of crime analysis

a number of cognitive biases that plague many analytical thinking and products.

Any tool is subject to misuse and $\mathrm{ACH}$ is not immune. Analysts can do any of the following:

(i) exclude evidence that contrasts with a favoured hypothesis; (ii) exclude certain

plausible hypotheses from consideration; (iii) either combine multiple pieces of evidence or split a single piece of evidence to manipulate the amount of disconfirmation against (un)desirable hypotheses; (iv) not employ proper reasoning; (v) fail to scrutinize the $\mathrm{ACH}$ matrix critically. In any case, because $\mathrm{ACH}$ is explicit, transparent and systematic these sins of commission and omission are much harder to perpetuate without detection. $\mathrm{ACH}$ makes analysis easier than an implicit, unstructured analysis process.

For future development, it would be illuminating for intelligence managers to provide hypothetical problems for analysts to work through the ACH method. Provided with a set of hypotheses and evidence, a group of analysts could populate the blank matrix individually and later compare what consistencies emerge. These exercises could vary in the level of detail provided, from overly prescriptive to self-directed. A study of inter-rater reliability at each stage would provide insightful empirical data for analyst training and professional development.

Crime science has recently emerged as a new approach to crime research and Laycock (2001) draws an analogy with medical science, an equally diverse collection of sciences with the related goals of disease prevention and the efficacious treatment of sickness. If the promise of greater analytical insight is to be realised in the law enforcement arena, crime analysts need to be provided with an intuitive but explicit model for testing putative 
hypotheses. Employing ACH in the analysis phase is a move toward a scientific approach to analysis.

\section{References}

Clarke, R. V. G., and Goldstein, H. (2003), "Thefts From Cars in Centre-City Parking Facilities: A Case Study in Implementing Problem-Oriented Policing." In ProblemOriented Policing: From Innovation to Mainstream, Crime Prevention Studies, ed. Johannes Knutsson. Monsey, NY: Criminal Justice Press, p. 257-298.

Cope, N. (2004), "Intelligence Led Policing or Policing Led Intelligence?: Integrating Volume Crime Analysis into Policing." British Journal of Criminology 44(2): 188-203.

Eck, J. E. (2002), Assessing responses to problems: An introductory guide for police problem-solvers. Washington DC: Office of Community Oriented Policing Studies.

Ekblom, P. (1988), Getting the best out of Crime Analysis. London, UK: Home Office.

Goldstein, H. (1979), "Improving policing: A problem-oriented approach." Crime and Delinquency 25(2): 236-58.

Goldstein, H. (2003), "On further developing Problem-Oriented Policing: The most criticial need, the major impediments and a proposal." In Problem-Oriented Policing: From Innovation to Mainstream, Crime Prevention Studies, ed. J. Knutsson. Monsey, NY: Criminal Justice Press, p. 13-48.

Goldstein, H. (1990), Problem-oriented Policing. New York: McGraw-Hill.

Groopman, J. (2007), How doctors think. New York: Houghton Mifflin. 
Heuer Jr., R. J. (1999), Psychology of Intelligence Analysis. Langley, VA: Center for the study of Intelligence, Central Intelligence Agency.

Hirschfield, A. (2005), "Analysis for intervention." In Handbook of Crime Prevention and Community Safety, ed. Nick Tilley. Cullompton: Willan Publishing, p. 629-673.

Innes, M., Fielding, N., and Cope, N. (2005), "The Appliance of Science?: The Theory and Practice of Crime Intelligence Analysis." British Journal of Criminology 45(1): 39-57.

Johnston, R. (2005), Analytic culture in the US Intelligence Community: An ethnographic study. Central Intelligence Agency.

Kebbell, M. R., Muller, D. A., and Martin, K. (2010), “Understanding and managing bias." In Dealing with uncertainties in policing serious crime, ed. G. Bammer. Canberra: ANU E Press, p. 87-97.

Knutsson, J., ed. (2003), 15 Problem-Oriented Policing: From Innovation to Mainstream. Monsey, NY: Criminal Justice Press.

Knutsson, J. (2003), "Introduction." In Problem-Oriented Policing: From Innovation to Mainstream, Crime Prevention Studies, ed. Johannes Knutsson. Monsey, NY: Criminal Justice Press, p. 1-12.

Laycock, G. (2001), Professorial Lecture Scientists of Politicians - who has the answer to crime? UCL, London: UCL.

Maxfield, M. G. (2001), Guide to Frugal Evaluation for Criminal Justice, Final Report. Washington DC: National Institute of Justice.

Mazerolle, L. G., and Ransley, J. (2005), Third party policing. Cambridge: Cambridge University Press. 
Ratcliffe, J. H. (2008), Intelligence-led Policing. Cullompton: Willan Publishing.

Read, T., and Tilley, N. (2000), Not Rocket Science? Problem-Solving and Crime Reduction. London: Home Office.

Sparrow, M. K. (2000), The regulatory craft: Controlling risks, solving problems, and managing compliance. Washington, DC: Brookings Institute Press.

Townsley, M., Johnson, S. D., and Pease, K. (2003), "Problem orientation, problem solving and organizational change." In Problem Oriented Policing: From Innovation to Mainstream, Crime Prevention Series, ed. Johannes Knutsson. Monsey, NY: Criminal Justice Press, p. 183-212.

Tversky, A., and Kahneman, D. (2000), "Judgment under uncertainty: Heuristics and biases." In Judgment and decision making: An interdisciplinary reader, Cambridge Series on Judgment and Decision Making, eds. Terry Connolly, Hal R. Arkes, and Kenneth R. Hammond. Cambridge: University of Cambridge Press, p. 35-52.

Valtorta, M. et al. (2005), "Extending Heuer's analysis of competing hypotheses method to support complex decision analysis." In Proceedings of the 2005 International Conference on Intelligence Analysis (IA-05),

Weisel, D. L. (2003), "The sequence of analysis in solving problems." In Problem Oriented Policing: From Innovation to Mainstream, Crime Prevention Studies, ed. J. Knutsson. Monsey, NY: Criminal Justice Press, p. 115-146.

Wheaton, K. J., and Chido, D. E. (2006), "Structured Analysis of Competing Hypotheses: Improving a Tested Intelligence Methodology." Competitive Intelligence Magazine 9(6): 12. 
i Testable is used throughout this article but the term falsifiable is equivalent. It is important that analysts generate explanations that are capable of being tested. This means that the variables or factors at play can be observed, measured and analysed. If a proposed explanation cannot be observed, it is unable to be subjected to rigorous analysis. For example, a common explanation for anti-social behaviour is bored youth. This is impossible to test because we do not have the means to measure boredom levels of young people. It may very well be right, but unless a factor can be measured, it lies beyond our ability to interpret.

ii Falsification is the idea that one seeks to disprove explanations rather than confirm them. This is because it is relatively easy to amass evidence in favour of something (c.f. confirmation bias). Instead, Karl Popper argued the strength of an argument should be assessed by the amount of evidence against it. The strongest explanations will have the least amount of evidence against them.

iii There have been attempts to describe evaluation for practitioners (Eck, 2002; Maxfield, 2001), but this is not our focus. We are interested in how analysis is conducted. While there is some overlap (assessment of evidence, appropriate use of data), analysis and evaluation are distinct enough tasks to limit our attention. 
LIST OF TABLES

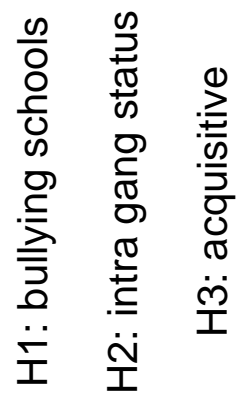

E1: mainly high school aged victims

$\begin{array}{lll}+ & 0 & - \\ ++ & - & - \\ + & + & 0 \\ 0 & - & + \\ + & + & -- \\ 0 & -2 & -5\end{array}$

Total

$\begin{array}{lll}0 & -2 & -5\end{array}$

Table 1: ACH matrix for robbery crime problem 


\section{Appendix}

This appendix outlines the reasoning behind the entries in the $\mathrm{ACH}$ matrix contained in Table 1. While the justification listed here is no more than a sentence, there is no restriction in practice. Analysts are encouraged to provide detailed reason why evidence confirms or disconfirms hypotheses. They may cite empirical work (although an argument about applicability if conducted in another city/country might be needed) or other analytic products. Appeals to experience or authority should be avoided. Theoretical justification is encouraged.

$\mathrm{E} 1$ is consistent with $\mathrm{H} 1$ because we would expect (school) bullying victims to be school aged.

$\mathrm{E} 1$ is neither consistent nor inconsistent with $\mathrm{H} 2$ because youth gangs are likely to favour "risky" targets to attack. There is a logic to selecting same-age victims but these will be low-status victims. High status victims will be adults who appear as if there are capable to defending themselves and own high value products.

$\mathrm{E} 1$ is inconsistent with $\mathrm{H} 3$ because lone adults are more suitable targets available than high school aged victims (who are normally in groups).

$\mathrm{E} 2$ is highly consistent with $\mathrm{H} 1$ because we would expect victims and offenders in school bullying to have very similar routine activities (allowing them to intersect in space and time). The observed concentration of the criminal incidents reflects the time window after 
school routine activities.

$\mathrm{E} 2$ is inconsistent with $\mathrm{H} 2$ because there is no reason why youth gangs would be constrained to a small time window (1500-1800 hours). The observed pattern may have more to do with the supply of suitable victims than the gang explanation.

$\mathrm{E} 2$ is inconsistent with $\mathrm{H} 3$ because similar reason as the $\mathrm{E} 2, \mathrm{H} 2$ justification above.

E3 is consistent with $\mathrm{H} 1$ because we would expect (school) bullying offenders to be school aged.

E3 is consistent with $\mathrm{H} 2$ because the gangs are described as youth gangs.

E3 is inconsistent with $\mathrm{H} 3$ because most robbers are young adult males, not school aged

E4 is neither consistent nor inconsistent with $\mathrm{H} 1$ because it is unclear the purpose of the kind of bullying at this school. Offenders may steal items for personal enjoyment, but most bullying is expressive in nature, not instrumental. On the other hand, it could be that the real extent of the bullying problem is masked. The reported incidents are the bullying incidents that involve personal loss, whereas physical/verbal assault go unreported.

E4 is inconsistent with $\mathrm{H} 2$ because this conflicts with the "violence as currency" observation.

E4 is consistent with $\mathrm{H} 3$ because financial gain is the purpose of acquisitive crimes.

E5 is consistent with $\mathrm{H} 1$ because power/status imbalance is a common feature of bullying. E5 is consistent with $\mathrm{H} 2$ because it matches the "violence as currency" observation. 
E5 is highly inconsistent with $\mathrm{H} 3$ because it is incongruent with the purpose of acquisitive crimes. 